Journal of

Applied

Crystallography

ISSN 0021-8898

Editor: Anke R. Kaysser-Pyzalla

\title{
Identification of unexpected hydrides in Mg-20 wt\% Dy alloy by high-brilliance synchrotron radiation
}

\author{
Weimin Gan, Yuanding Huang, Lei Yang, Karl Ulrich Kainer, Miao Jiang, \\ Heinz-Günter Brokmeier and Norbert Hort
}

J. Appl. Cryst. (2012). 45, 17-21

Copyright (C) International Union of Crystallography

Author(s) of this paper may load this reprint on their own web site or institutional repository provided that this cover page is retained. Republication of this article or its storage in electronic databases other than as specified above is not permitted without prior permission in writing from the IUCr.

For further information see http://journals.iucr.org/services/authorrights.html

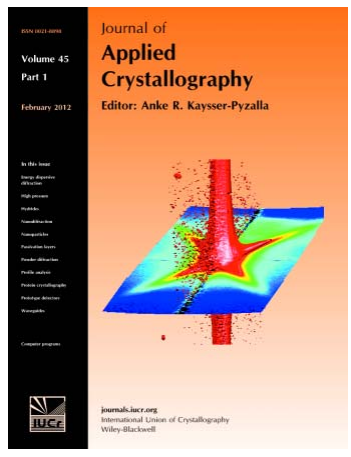

Journal of Applied Crystallography covers a wide range of crystallographic topics from the viewpoints of both techniques and theory. The journal presents papers on the application of crystallographic techniques and on the related apparatus and computer software. For many years, the Journal of Applied Crystallography has been the main vehicle for the publication of small-angle scattering papers and powder diffraction techniques. The journal is the primary place where crystallographic computer program information is published.

Crystallography Journals Online is available from journals.iucr.org 
Journal of

Applied

Crystallography

ISSN 0021-8898

Received 17 October 2011

Accepted 9 December 2011

(C) 2012 International Union of Crystallography Printed in Singapore - all rights reserved

\section{Identification of unexpected hydrides in Mg-20 wt\% Dy alloy by high-brilliance synchrotron radiation}

\author{
Weimin Gan, ${ }^{\mathrm{a} *}$ Yuanding Huang, ${ }^{\mathrm{a}}$ Lei Yang, ${ }^{\mathrm{a}}$ Karl Ulrich Kainer, ${ }^{\mathrm{a}}$ Miao Jiang, \\ Heinz-Günter Brokmeier ${ }^{\mathrm{a}, \mathrm{b}}$ and Norbert Hort ${ }^{\mathrm{a}}$ \\ anstitute of Materials Research, Helmholtz-Zentrum Geesthacht, D-21502 Geesthacht, Germany, \\ and ${ }^{\mathbf{b}}$ Institute for Materials Science and Engineering, Clausthal University of Technology, D-38678 \\ Clausthal-Zellerfeld, Germany. Correspondence e-mail: weimin.gan@hzg.de
}

\begin{abstract}
An unexpected precipitate phase was observed in $\mathrm{Mg}-20 \mathrm{wt} \%$ Dy alloy, with a cuboid morphology not compatible with any shown in the $\mathrm{Mg}-\mathrm{Dy}$ binary phase diagram. As observed by scanning electron microscopy and energy-dispersive $\mathrm{X}$-ray analysis, the ratio of atomic percent of $\mathrm{Dy}$ to $\mathrm{Mg}$ is very high in these particles, probably largely because of the poor spatial resolution of that technique but already showing the mismatch with any previously characterized $\mathrm{Mg}-\mathrm{Dy}$ compound. High-brilliance synchrotron diffraction and transmission electron microscopy experiments confirmed that these particles are composed of $\mathrm{DyH}_{2}$. They are formed during sample preparation at room temperature when hydrogen-containing sources such as water are used.
\end{abstract}

\section{Introduction}

The applications of magnesium alloys have been expanding because they are being developed not only as structural materials for transportation or other industrial uses, but also as biodegradable medical implant materials (Friedrich \& Mordike, 2006; Hort et al., 2010; Yang et al., 2011). The rare earth (RE) metals have active chemical properties, being the most vigorous alloying elements for $\mathrm{Mg}$, and hence they can play important roles in removing impurities and improving the performance of alloys. The addition of REs to magnesium reduces the hydrogen content (Busk \& Bobalek, 1935) and the porosity in as-cast magnesium alloys (Avedesian \& Baker, 1999). Compared with non-RE-containing magnesium alloys, the RE-containing alloys have better corrosion resistance (Birbilis et al., 2009; Liu et al., 2009). Results from Luo et al. (2009) show that the addition of $0.2 \%$ Y to AZ91 alloy increases its corrosion resistance by seven times. Owing to their suitable mechanical properties and acceptable corrosion resistance, $\mathrm{Mg}-\mathrm{RE}$ alloys have recently come to be regarded as one of the most potentially degradable biomaterials (Hort et al., 2010; Hänzi et al., 2009; Quach et al., 2008; Feyerabend et al., 2010; Witte, 2010; Witte et al., 2008).

From their preparation to their final applications, magnesium alloys are normally subjected to a hydrogen-containing environment. It is of particular interest to investigate the possible interactions between $\mathrm{RE}$ and $\mathrm{H}$ in $\mathrm{Mg}-\mathrm{RE}$ alloys. Yang et al. (2009) reported that $\mathrm{NdH}_{2}$ is formed in $\mathrm{Mg}-2 \mathrm{wt} \%$ $\mathrm{Nd}$ alloy with $\mathrm{T} 4$ treatment. The formation of $\mathrm{NdH}_{2}$ was attributed to the reaction of $\mathrm{Nd}$ with previously dissolved $\mathrm{H}$ during casting. Recently, a different explanation was given by Peng et al. (2011). They suggested that the formation of hydride in $\mathrm{Mg}-\mathrm{Gd}$ alloys can also proceed during sample preparation or mechanical deformation if they are subjected to an $\mathrm{H}$-containing environment. The hydride could be formed even at room temperature by a reaction with external $\mathrm{H}$ sources such as water vapour or water.

To clarify further the possible formation of hydrides during sample preparation at room temperature and to confirm whether it is caused by surface reactions, the present work investigates the phases present in $\mathrm{Mg}-20 \mathrm{wt} \% \mathrm{Dy}$, which is currently under development as a biomaterial for application in medicine (Yang et al., 2011). The main experimental means consist of using the newly developed high-energy materials science (HEMS, Helmholtz-Zentrum Geesthacht) beamline at the German high-brilliance synchrotron radiation storage ring PETRA III, DESY, Hamburg (Schell et al., 2008). The high energy in combination with high flux at HEMS provides many advantages over conventional methods for phase characterization of microprecipitates, such as a high penetration depth for bulky and coarse-grained materials. Moreover, sample preparation is very easy and the measurements run very quickly in a non-destructive manner.

\section{Experimental}

High-purity $\mathrm{Mg}$ was melted in a mild steel crucible under a protective atmosphere $\left(\mathrm{Ar}+0.2 \% \mathrm{SF}_{6}\right)$, and $20 \mathrm{wt} \%$ pure $\mathrm{Dy}$ was added at a melt temperature of $993 \mathrm{~K}$. The melt was stirred at $200 \mathrm{r} \mathrm{min}^{-1}$ for $30 \mathrm{~min}$. After that, the melt was cast using the directly chilled permanent mould casting method (Peng et al., 2010; Elsayed et al., 2011). The melt was poured into a mould preheated at $773 \mathrm{~K}$. The filled mould was held at $943 \mathrm{~K}$ for $30 \mathrm{~min}$ under protective gas. The whole steel crucible, with the melt, was then lowered into cooling water at 
a rate of $10 \mathrm{~mm} \mathrm{~s}^{-1}$. When the bottom of the steel crucible touched the water, it was stopped for $1 \mathrm{~s}$. As soon as the level of the melt was in alignment with the water level (Peng et al., 2010), the solidification process was finished. The size of the ingot is $60 \times 120 \times 200 \mathrm{~mm}$. Solution treatment was carried out at $793 \mathrm{~K}$ for $24 \mathrm{~h}$, followed by water quenching. Ageing treatment was carried out at $523 \mathrm{~K}$ for $16 \mathrm{~h}$, followed by air cooling.

Samples for microstructural observation were prepared in two ways:

(i) After cutting, the specimens were ground and mechanically polished with water.

(ii) After cutting, the samples were ground and mechanically polished with organic solvents such as high-purity ethanol, instead of water. After the specimens had been further electropolished, they were immediately subjected to microstructural observation.

Microstructures were investigated using a Zeiss Ultra 55 scanning electron microscope (Carl Zeiss GmbH, Oberkochen, Germany) equipped with energy-dispersive X-ray analysis (EDX). Specimens for transmission electron microscopy (TEM) were mechanically ground to about $120 \mu \mathrm{m}$ thickness with the assistance of water and then thinned by electropolishing in a twin jet system using a solution of $2.5 \%$ $\mathrm{HClO}_{4}$ and $97.5 \%$ ethanol at about $228 \mathrm{~K}$ and a voltage of 40 V. TEM examinations were carried out on a Philips CM 200 instrument with an EDX system operating at $200 \mathrm{kV}$.

Synchrotron irradiation was performed at HEMS with a wavelength of $0.177 \AA$ ( $70 \mathrm{keV})$. The $0.5 \times 1 \mathrm{~mm}$ sized beam penetrated through the polished surface of the specimens. To increase the investigated volume, the specimen was rotated by $\omega= \pm 20^{\circ}$ around an axis normal to the beam during the $10 \mathrm{~s}$ irradiation time. The Debye-Scherrer rings were recorded by a Marresearch mar345 image-plate detector. The integrated intensities of the images were obtained using the software FIT2D (Hammersley, 1997). The diffraction patterns were characterized according to the PDF-2 database from the International Centre for Diffraction Data (ICDD, 2011).

\section{Results}

Normally, in $\mathrm{Mg}-\mathrm{RE}$ binary hypoeutectic alloys only one second phase (Mg-RE intermetallics) exists after solidification (Nayeb-Hashemi \& Clark, 1988). Interestingly, when the present samples of the as-cast $\mathrm{Mg}-20 \mathrm{wt} \%$ Dy alloy were prepared using method (i), two second phases with different contrasts were observed: white particles with a high content of Dy and grey particles with a relatively low content of Dy (Fig. 1a). The formation of the white particles seems not to be affected by the heat treatment; they are observed not only in the as-cast samples but also in the heat-treated samples (Figs. $1 b$ and $1 c$ ). These particles have a cuboid shape and appear to be lying on the surface. In the as-cast samples, the white particles are normally observed near the Mg-Dy intermetallics at the dendritic or grain boundaries, and they can be observed over the matrix in the heat-treated samples. The size of these white particles is from about $30 \mathrm{~nm}$ to several micrometres. In the heat-treated samples, the quantity of the grey $\mathrm{Mg}-\mathrm{RE}$ particles largely decreases. However, the quantity of the white cuboid particles shows no significant difference from the as-cast samples.

Fig. 2 shows a comparison of microstrutural characteristics between specimens prepared by methods (i) and (ii). Only the microstructures of the solution-treated specimens are shown as examples, because the disturbance from $\mathrm{Mg}-\mathrm{Dy}$ intermetallics is alleviated after solution treatment. As shown in Fig. 2(a), by using method (ii) to prepare a specimen, cuboid particles with a high Dy content are barely observed. Over the matrix, only some remaining $\mathrm{Mg}-\mathrm{Dy}$ particles are found. When a specimen is prepared using method (i), then besides the $\mathrm{Mg}-$ Dy intermetallics, cuboid particles are observed in great number (Figs. $2 b, 2 c$ and $2 d$ ). These particles lie on the surface and their sizes vary between about 0.5 and $5 \mu \mathrm{m}$. The EDX analyses demonstrate that the ratio of Dy to $\mathrm{Mg}$ in these particles is more than 1 . In fact, the actual ratio might be much

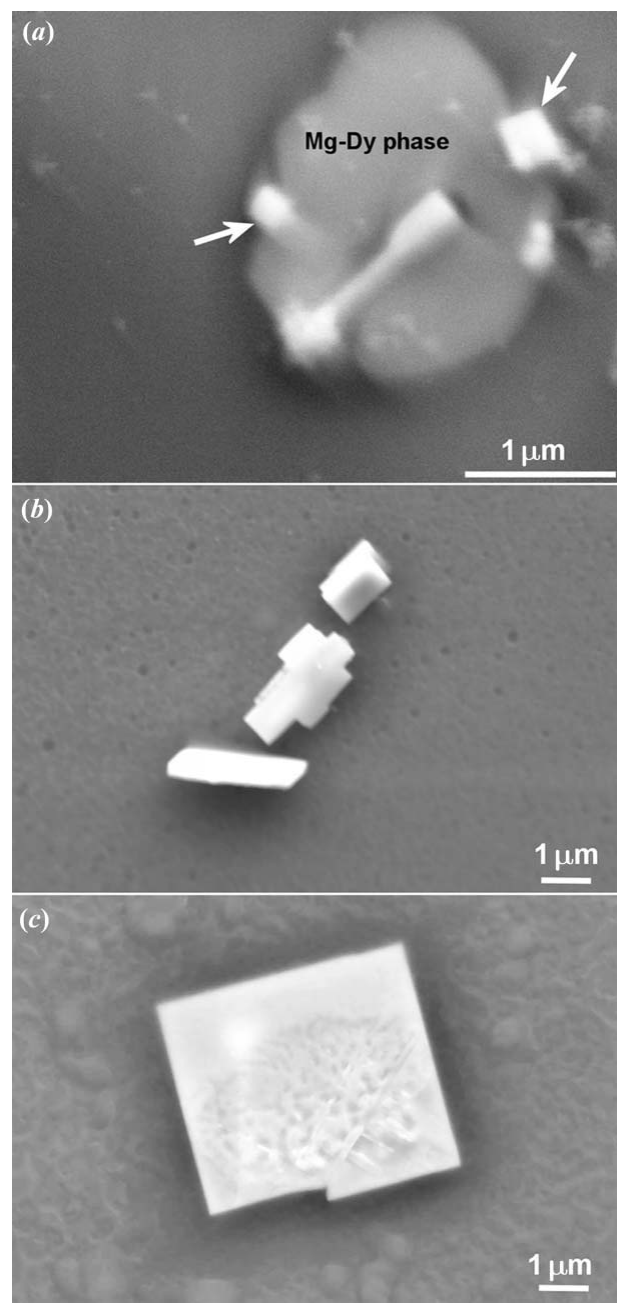

Figure 1

Scanning electron micrographs showing the existence of white cuboid particles with a very high Dy content in $\mathrm{Mg}-20 \mathrm{wt} \%$ Dy samples using sample preparation method (i). (a) As cast; note the white particles indicated by arrows. (b) Solutionized at $793 \mathrm{~K}$ for $24 \mathrm{~h}$ then water quenched. (c) Solutionized at $793 \mathrm{~K}$ for $24 \mathrm{~h}$ followed by water quenching and then ageing at $523 \mathrm{~K}$ for $16 \mathrm{~h}$. 


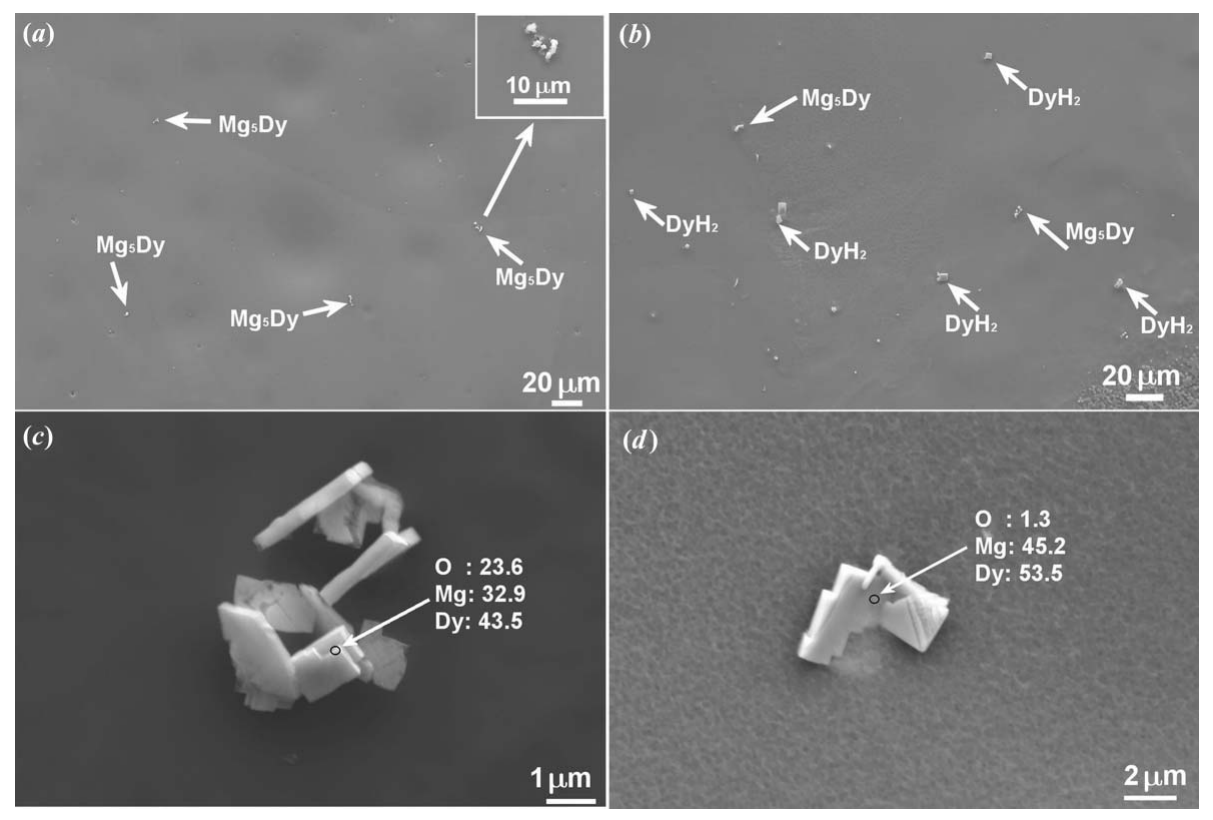

Figure 2

Scanning electron micrographs showing the particles in $\mathrm{Mg}-20 \mathrm{wt} \%$ Dy alloy with $\mathrm{T} 4$ treatment. (a) Machined and polished in a dry environment [preparation method (ii)]. (b) Machined and polished with water [preparation method (i)]; cuboid particles are observed. (c) Cluster of cuboid particles with high Dy and O contents in a sample prepared using method (i). (d) Cuboid particle with a very high Dy content in a sample prepared using method (i). Numbers shown in the pictures are atomic percent.
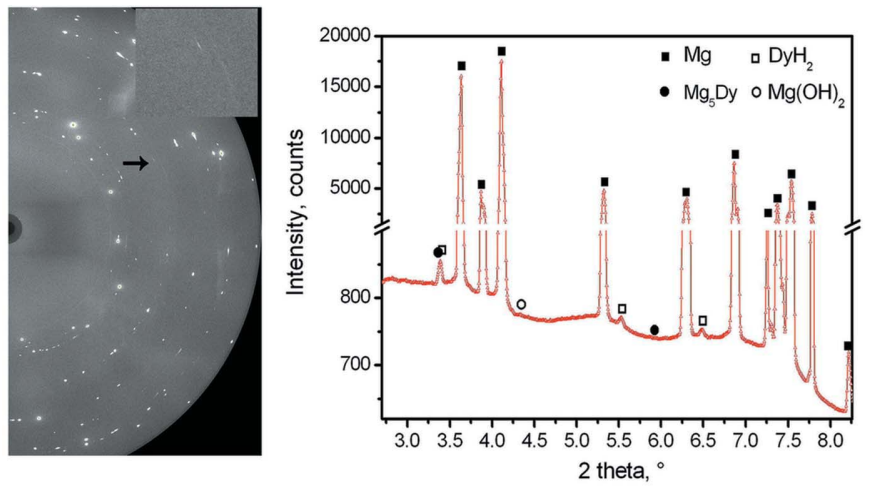

(a)
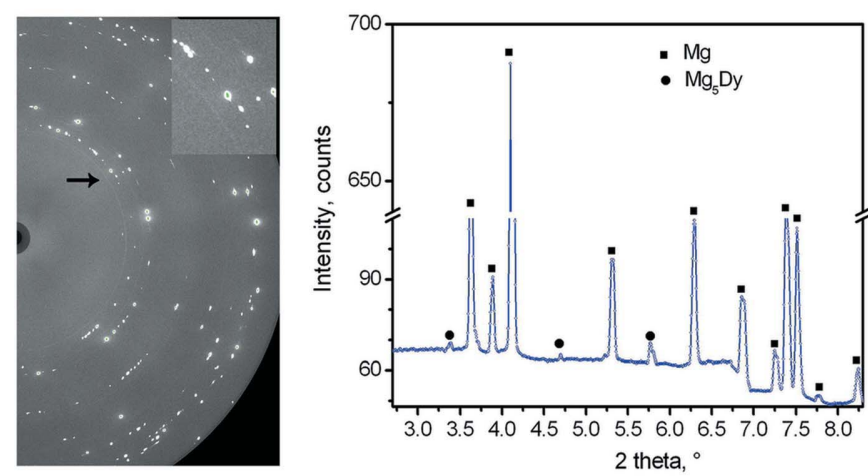

(b)

Figure 3

Parts of the two-dimensional diffraction images (left) and their sum diffraction patterns (right) for the solution-treated specimens prepared by (a) method (i) and (b) method (ii). higher than the experimental value because part of the $\mathrm{Mg}$ composition for these particles, obtained by EDX analysis, comes from the contribution of the magnesium matrix, as a result of their small sizes of less than $2 \mu \mathrm{m}$. Such a phase with a ratio of $\mathrm{Dy}$ to $\mathrm{Mg}$ greater than 1 cannot be found in the Mg-Dy binary phase diagram (Nayeb-Hashemi \& Clark, 1988). It could be one phase of Dy-containing oxides, carbides or hydrides because of the poor detection capabilities of EDX for light elements such as hydrogen and carbon.

The synchrotron diffraction images and their sum patterns of solutiontreated specimens prepared by methods (i) and (ii) are shown in Figs. 3(a) and $3(b)$, respectively. Besides the strongly scattered diffraction points caused by large $\mathrm{Mg}$ grains, weak diffraction from the secondary phases is still clearly observed, as marked by arrows in the figures. In the solution-treated sample prepared by method (i) there are three phases: an equilibrium $\beta$ phase $\mathrm{Mg}_{5}$ Dy with a cubic structure (space group $F \overline{4} 3 m, a=22.2344 \AA), \operatorname{Mg}(\mathrm{OH})_{2}$ with a hexagonal structure (space group $P \overline{3} m 1, a=3.144, c=4.777 \AA$ ) and $\mathrm{DyH}_{2}$ with a cubic structure (space group $\mathrm{Fm} \overline{3} m, a=$ $5.201 \AA$ ). The three reflections with $2 \theta=3.39,5.52$ and $6.48^{\circ}$ correspond to diffraction from the (111), (022) and (113) crystallographic planes of $\mathrm{DyH}_{2}$, respectively. In the solutiontreated sample prepared by method (ii), only the intermetallic $\mathrm{MgDy}_{5}$ is identified.

\section{Discussion}

Based on the above results, the cuboid particles should be $\mathrm{DyH}_{2}$. The $\mathrm{Mg}-\mathrm{Dy}$ intermetallic is $\mathrm{Mg}_{5} \mathrm{Dy}$, which is in agreement with what is shown in the Mg-Dy phase diagram. EDX analysis of the cuboid $\mathrm{DyH}_{2}$ particles, as shown in Fig. 4, gave the result 25.6 at.\% $\mathrm{Mg}, 70.1$ at.\% Dy and 4.3 at.\% O. Sometimes $\mathrm{Mg}(\mathrm{OH})_{2}$ was observed, which is in agreement with the results obtained by synchrotron diffraction. In the region of $\mathrm{Mg}(\mathrm{OH})_{2}, \mathrm{EDX}$ analysis indicated that the $\mathrm{Mg}$, Dy and $\mathrm{O}$ contents are 48.3,1.3 and 50.4 at. \%, respectively. According to this phenomenon and combined with consideration of the sample preparation process, the formation mechanism of $\mathrm{DyH}_{2}$ can be explained as follows.

Firstly, magnesium reacts with water to produce hydrogen:

$$
\mathrm{Mg}+2 \mathrm{H}_{2} \mathrm{O} \rightarrow \mathrm{Mg}(\mathrm{OH})_{2}+2[\mathrm{H}]
$$

Secondly, the hydrogen produced reacts with Dy to form $\mathrm{DyH}_{2}$ :

$$
\mathrm{Dy}+2[\mathrm{H}] \rightarrow \mathrm{DyH}_{2} \text {. }
$$


At room temperature, the free energies of $\mathrm{Mg}(\mathrm{OH})_{2}$ and $\mathrm{MgO}$ are 934.5 and $609.3 \mathrm{~kJ} \mathrm{~mol}^{-1}$, respectively (Barin, 1993). Hence, $\mathrm{Mg}(\mathrm{OH})_{2}$ would be formed preferentially. These observed $\mathrm{DyH}_{2}$ particles should be present on the surface of the samples. In fact, they are caused by surface reactions when the samples are ground and polished with water. This is why the $\mathrm{DyH}_{2}$ particles sometimes appear to be lying on the surface. When the solution-treated sample was prepared in a dry environment, no $\mathrm{DyH}_{2}$ particles were detected, which can be verified from the characterization from the synchrotron diffraction patterns (Fig. 3b). No surface $\mathrm{DyH}_{2}$ was observed by scanning electron microscopy either, as shown in Fig. 2(a). These results exclude the possibility that $\mathrm{DyH}_{2}$ particles, after solution treatment, are formed in the interior of the materials owing to the prior existence of dissolved hydrogen. Perhaps because the obtained Mg-20 wt\% Dy alloy contains much less pre-existing hydrogen, no hydrides were formed in the interior of the samples by solution treatment.

The $\mathrm{H}$ for the present formation of $\mathrm{DyH}_{2}$ comes from environmental sources, such as water, rather than pre-existing hydrogen that could have been dissolved in the ingots during casting and solidification. Yang, Fu and co-workers reported that the formation of $\mathrm{ZrH}_{2}$ and $\mathrm{NdH}_{2}$ are caused by the reaction of alloying elements with such pre-existing hydrogen during solution treatment (Yang et al., 2009; Fu et al., 2007). Indeed, their results are not contradictory with the current
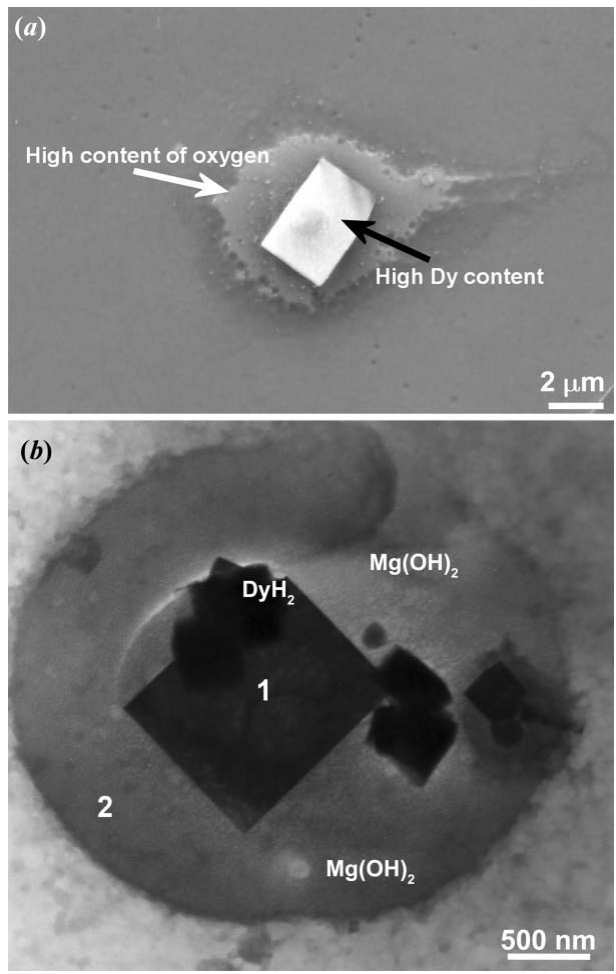

\section{Figure 4}

Micrographs showing magnesium hydroxide around the $\mathrm{DyH}_{2}$ particles in $\mathrm{Mg}-20 \mathrm{wt} \%$ Dy alloy. (a) Secondary electron image by scanning electron microscopy. The specimen was prepared using method (i). (b) Bright-field image by TEM. During grinding and thinning the specimen was in contact with water. EDX results for point 1: 25.6 at. $\% \mathrm{Mg}, 70.1$ at.\% Dy and 4.3 at. \% O; and for point 2: 48.3 at. \% Mg, 1.3 at.\% Dy and 50.4 at.\% O. ones. The present results illustrate that, when $\mathrm{Mg}-20 \mathrm{wt} \%$ Dy alloy contains no or very little pre-existing hydrogen, hydrides can still be formed on the surface even at room temperature by the reaction of the relevant elements with external hydrogen-containing sources such as water.

\section{Conclusions}

Using high-brilliance synchrotron diffraction an unexpected hydride, $\mathrm{DyH}_{2}$, was successfully identified. This hydride, with a cuboid shape, can be formed on the surface of Mg-20 wt \% Dy samples if they are machined and polished with water at room temperature. Heat treatments such as solid solution or ageing treatments have no influence on the formation of hydrides for the present $\mathrm{Mg}-20 \mathrm{wt} \%$ Dy materials. The formation mechanism of $\mathrm{DyH}_{2}$ can be explained according to equations (1) and (2). In contrast, the formation of hydrides is prevented in the specimens if they are machined and polished in a dry environment.

The authors thank Dr Carsten Blawert for fruitful discussions, and Mr Willi Punessen, Mr Uwe Lorenz and Mr Günter Meister for technical assistance. We are grateful for instrumental support at HEMS from Dr N. Schell, Mr B. Schwebke and Mr R. Kirchhof under a proposal accepted at DESY.

\section{References}

Avedesian, M. M. \& Baker, H. (1999). Editors. ASM Specialty Handbook: Magnesium and Magnesium Alloys. Materials Park: ASM International.

Barin, I. (1993). Editor. Thermochemical Data of Pure Substances: $\mathrm{La}-\mathrm{Zr}$. Weinheim: VCH.

Birbilis, N., Easton, M. A., Sudholz, A. D., Zhu, S. M. \& Gibson, M. A. (2009). Corros. Sci. 51, 683-689.

Busk, R. S. \& Bobalek, E. G. (1935). Trans. AIME, 171, 261-276.

Elsayed, F. R., Hort, N., Salgado-Ordorica, M. A. \& Kainer, K. U. (2011). Mater. Sci. Forum, 690, 65-68.

Feyerabend, F., Fischer, J., Holtz, J., Witte, F., Willumeit, R., Drücker, H., Vogt, C. \& Hort, N. (2010). Acta Biomater. 6, 1834-1842.

Friedrich, H. E. \& Mordike, B. L. (2006). Editors. Magnesium Technology Metallurgy, Design Data, Applications. Heidelberg: Springer-Verlag.

Fu, P. H., Peng, L. M., Jiang, H. Y., Zhai, C. Q., Gao, X. \& Nie, J. F. (2007). Mater. Sci. Forum, 546-549, 97-100.

Hammersley, A. P. (1997). FIT2D: An Introduction and Overview. ESRF Internal Report ESRF97HA02T. ESRF, Grenoble, France.

Hänzi, A. C., Gunde, P., Schinhammer, M. \& Uggowitzer, P. J. (2009). Acta Biomater. 5, 162-171.

Hort, N., Huang, Y., Fechner, D., Störmer, M., Blawert, C., Witte, F., Vogt, C., Drücker, H., Willumeit, R., Kainer, K. U. \& Feyerabend, F. (2010). Acta Biomater. 6, 1714-1725.

ICDD (2011). PDF-2. International Centre for Diffraction Data, Newtown Square, Pennsylvania, USA. http://www.icdd.com.

Liu, W., Cao, F., Chang, L., Zhang, Z. \& Zhang, J. (2009). J. Corros. Sci. 51, 1334-1343.

Luo, T. J., Yang, Y. S., Li, Y. J. \& Dong, X. G. (2009). Electrochim. Acta, 54, 6433-6437.

Nayeb-Hashemi, A. A. \& Clark, J. B. (1988). Editors. Phase Diagram of Binary Magnesium Alloys. Materials Park: ASM International.

Peng, Q., Huang, Y., Meng, J., Li, Y. \& Kainer, K. U. (2011). Intermetallics, 19, 382-389. 
Peng, Q., Huang, Y., Zhou, L., Hort, N. \& Kainer, K. U. (2010). Biomaterials, 31, 398-403.

Quach, N.-C., Uggowitzer, P. J. \& Schmutz, P. (2008). C. R. Chim. 11, 1043-1055.

Schell, N., Martins, R. V., Beckmann, F., Ruhnau, H. U., Kiehn, R. \& Schreyer, A. (2008). Mater. Sci. Forum, 571-572, 261-266.

Witte, F. (2010). Acta Biomater. 6, 1680-1692.
Witte, F., Hort, N., Vogt, C., Cohen, S., Kainer, K. U., Willumeit, R. \& Feyerabend, F. (2008). Curr. Opin. Solid State Mater. Sci. 12, 63-72. Yang, L., Huang, Y., Peng, Q., Feyerabend, F., Kainer, K. U., Willumeit, R. \& Hort, N. (2011). Mater. Sci. Eng. B, 176, 18271834.

Yang, Y., Peng, L., Fu, P., Hu, B. \& Ding, W. (2009). J. Alloys Compd. 485, 245-248. 